\title{
ON THE MATRIX HARMONIC MEAN
}

\section{Mohammad SABABHeh}

Abstract. The main goal of this article is to present new types of inequalities refining and reversing inequalities of the harmonic mean of scalars and matrices. Furthermore, implementing the spectral decomposition of positive matrices, we present a new type of inequalities treating certain harmonic matrix perturbation. Mathematics subject classification (2010): 15A39, 15B48, 47A30, 47A63.

Keywords and phrases: Positive matrices, matrix means, norm inequalities, harmonic means, Heinz means.

\section{REFERENCES}

[1] T. Ando, Matrix Young inequalities, Oper. Theory Adv. Appl. 75 (1995), 33-38.

[2] M. BAKHERAD, M. KRNIC AND M. S. Moslehian, Reverse Young-type inequalities for matrices and operators, Rocky Mountain J. Math. 46 (2016), 1089-1105.

[3] R. B hatia, Matrix analysis, Springer-Verlag, New York, 1997.

[4] R. Bhatia AND K. R. PARThasarathy, Positive definite functions and operator inequalities, Bull. London Math. Soc. 32 (2000), 214-228.

[5] R. BHATIA, Interpolating the arithmetic-geometric mean inequality and its operator version, Linear Algebra Appl. 413 (2006) 355-363.

[6] C. Conde, Young type inequalities for positive operators, Ann. Funct. Anal. 4 (2013), 144-152.

[7] O. Hirzallah AND F. KitTAneh, Matrix Young inequalities for the Hilbert-Schmidt norm, Linear Algebra Appl. 308 (2000), 77-84.

[8] R. KaUR AND M. Singh, Complete interpolation of matrix versions of Heron and Heinz means, Math. Inequal. Appl. 16 (2013), 93-99.

[9] F. Kittaneh, M. Sal Moslehian and M. Sababheh, Quadratic interpolation of the Heinz means, Math. Inequal. Appl. 21, 3 (2018), 739-757.

[10] F. Kittaneh, On the convexity of the Heinz mean, Integr. Equ. Oper. Theory 68 (2010), 519-527.

[11] F. Kittaneh, Norm inequalities for fractional powers of positive operators, Lett. Math. Phys. 27 (1993), 279-285.

[12] F. Kittaneh and Y. Manasrah, Improved Young and Heinz inequalities for matrices, J. Math. Anal. Appl. 36 (2010), 262-269.

[13] M. KRnić, More accurate Young, Heinz, and Holder inequalities, Period. Math. Hung. 71 (2015), $78-91$.

[14] H. KosAKI, Arithmetic-geometric mean and related inequalities for operators, J. Funct. Anal. 156 (1998), 429-451.

[15] W. LiAO AND J. Wu, Reverse arithmetic-harmonic mean and mixed mean operator inequalities, J. Inequal. Appl. 2015:215.

[16] M. SABABHEH, Log and harmonically log-convex functions related to matrix norms, Operators and Matrices, in press.

[17] M. SababHeH, Integral inequalities of the Heinz means as convex functions, J. Math. Ineq. 10 (2) (2016), 313-325.

[18] J. ZhaO AND J. Wu, Operator inequalities involving improved Young and its reverse inequalities, J. Math. Anal. Appl. 421 (2015), 1779-1789.

[19] H. Zuo, G. SHI AND M. FuJII, Refined Young inequality with Kantorovich constant, J. Math. Inequal. 5 (4) (2011), 551-556. 